\title{
ESTRATÉGIAS DE AERAÇÃO DE MILHO ARMAZENADO: TEMPERATURA E TEOR DE ÁGUA
}

\section{VÂNIA R. G. NASCIMENTO ${ }^{1}$, MARLENE R. DE QUEIROZ ${ }^{2}$}

RESUMO: O objetivo deste trabalho consistiu em avaliar e comparar o desempenho de três diferentes estratégias de aeração de milho armazenado: aeração contínua, aeração noturna e aeração em condições de equilíbrio higroscópico entre os grãos e o ar ambiente. Utilizaram-se grãos de milho com dois níveis de teor de água; $11 \%$ e $17 \%$. Realizou-se monitoramento contínuo da temperatura, e amostras de grãos foram retiradas durante os ensaios para análise do teor de água. Observou-se que todas as estratégias de aeração favoreceram a redução da temperatura nos grãos secos $(11 \%)$ e umidificados (17\%). A estratégia de aeração contínua foi a mais eficiente em grãos úmidos, uma vez que evitou aquecimento dos grãos durante o armazenamento. Nenhuma estratégia de aeração manteve a temperatura homogênea no interior dos grãos durante a armazenagem. Ela variou conforme as condições climáticas. O teor de água dos grãos sofreu variações durante os ensaios, com tendência de secagem ao final do processo.

PALAVRAS-CHAVE: armazenagem, conservação de grãos, temperatura, teor de água.

\section{DIFFERENT AERATION STRATEGIES FOR STORED CORN: TEMPERATURE AND MOISTURE CONTENT}

\begin{abstract}
The objective of this research was to evaluate and compare the performance of three different strategies for aeration of grain corn. The strategies investigated were: continuous aeration, night aeration, and aeration in equilibrium moisture content between the grain and the ambient air. Corn at two different moisture content levels, $11 \%$ and $17 \%$ were used. Continuous monitoring of grain temperature through sensors was carried out, and grain samples were taken during the experiments for determination of moisture content. All used aeration strategies favored temperature reduction in dry (11\%) and moist (17\%) grains. The continuous aeration strategy was the most efficient in wet grains, since heating of grains during storage was avoided. No aeration strategy maintained the homogeneous temperature inside the grain during the storage; it varied according to climatic conditions. The moisture content of grains has suffered variations during the experimental period, with a tendency of drying at the end of the process.
\end{abstract}

KEYWORDS: storage, grain conservation, temperature, moisture content.

\section{INTRODUÇÃO}

Os principais fatores que interferem na qualidade dos grãos durante a armazenagem são a temperatura e o teor de água dos mesmos, e estão relacionados com a respiração do produto e a presença de microrganismos (SILVA, 2000). OLIVEIRA et al. (2007) alertam que, durante o armazenamento em silos, os grãos ficam sujeitos às alterações da temperatura ambiente, que aliadas ao teor de água dos grãos influem diretamente na ocorrência de insetos e microrganismos. Para a manutenção da qualidade de grãos, utiliza-se o processo de aeração, que consiste na redução da temperatura dos mesmos por meio da passagem forçada de ar ambiente pela massa de grãos.

A operação de um sistema de aeração pode ser manual ou automatizada com o uso de controladores, termostatos e/ou umidostatos, que consideram, respectivamente, a temperatura e a

\footnotetext{
${ }^{1}$ Eng ${ }^{\text {a }}$ Agrícola, Doutoranda em Engenharia Agrícola, FEAGRI-UNICAMP, Campinas - SP, vania.guimaraes@ feagri.unicamp.br.

${ }^{2}$ Eng $^{\mathrm{a}}$ Agrícola, Professora Titular, FEAGRI-UNICAMP, Campinas - SP, marlene@ feagri.unicamp.br.

Recebido pelo Conselho Editorial em: 20-4-2010

Aprovado pelo Conselho Editorial em: 23-5-2011
} 
umidade relativa do ar como parâmetros. Existem ainda sistemas que são operados de acordo com informações de sensores de temperatura instalados no interior da massa de grãos armazenada.

RANALLI et al. (2002) compararam o manejo tradicional de um administrador de propriedade agrícola com a operação de termostato e umidostato. Verificaram que a redução de temperatura dos grãos com o controlador foi maior quando comparada à aeração tradicional. CASADA et al. (2002) realizaram aeração controlada por termostato e verificaram melhores temperaturas para o controle de insetos nos grãos aerados em relação aos armazenados sem aeração. Entretanto, observaram que, no período noturno, embora a temperatura fosse baixa, a umidade relativa do ar era alta, o que provocou um ligeiro reumedecimento e aumento da temperatura dos grãos, devido ao efeito do calor latente.

SAUER (1992) explica que, em aeração utilizando ar com umidade relativa superior à de equilíbrio higroscópico entre os grãos e o ar, ocorre elevação do teor de água dos grãos até a condição de equilíbrio ser alcançada. Se o processo for adiabático, o calor de condensação da água adicionada aos grãos também aquece o ar.

Abordagens teóricas dos estudos de aeração foram reportadas por OLIVEIRA et al. (2007) e DEVILLA et al. (2005). OLIVEIRA et al. (2007) estudaram teórica e experimentalmente a dinâmica de resfriamento de grãos de soja armazenados em silo com aeração, utilizando dois modelos matemáticos. Concluíram que o modelo baseado na conservação de energia obteve melhor representação dos dados experimentais.

DEVILLA et al. (2005) utilizaram a técnica de elementos finitos para modelar a distribuição de ar em grãos de milho armazenados em silo metálico com sistema de aeração por dutos de distribuição do ar. Verificaram a ocorrência de regiões de baixa velocidade do ar no fundo do silo, proporcionando zonas com pouca aeração. Os autores ressaltam que esse fato pode comprometer o resfriamento dos grãos nessas zonas. Na superfície da massa de grãos, entretanto, a velocidade do ar tendeu a ser uniforme.

A hipótese deste trabalho baseia-se na teoria de que a aeração permite melhorar as condições de armazenamento, reduzindo e homogeneizando a temperatura dos grãos, porém existem estratégias de aeração tecnicamente mais eficientes.

O objetivo deste trabalho foi comparar o desempenho de três estratégias de aeração quanto à eficiência na redução e na homogeneização da temperatura e na manutenção do teor de água dos grãos de milho armazenados secos (11\%) e úmidos (17\%). As estratégias foram as seguintes: aeração contínua, noturna e em condições de equilíbrio higroscópico entre os grãos e o ar.

\section{MATERIAIS E MÉTODOS}

\section{Equipamento}

Os ensaios de aeração foram realizados em seis silos de pequena escala, construídos a partir de tambores de óleo diesel com dimensões de 0,57 $\mathrm{m}$ de diâmetro e $0,85 \mathrm{~m}$ de altura, sendo a altura do plenum de $0,15 \mathrm{~m}$, o que resultou em coluna de grãos de $0,70 \mathrm{~m}$ de altura. Realizou-se isolamento externo dos silos de poliestireno expandido (isopor) de 0,01 m de espessura. Os silos possuíam aberturas laterais ao longo da altura para a retirada de amostras, posicionadas nas alturas de $0,31 \mathrm{~m}, 0,52 \mathrm{~m}$ e $0,74 \mathrm{~m}$ em relação à base.

A aeração foi realizada por microventiladores elétricos axiais da marca Qualitas, modelo Q40SD4, vazão máxima de 3,0 $\pm 5 \% \mathrm{~L} \mathrm{~s}^{-1}$, pressão máxima de 3,0 mmCA, potência nominal de $1,2 \mathrm{~W}$. Um inversor de frequência foi utilizado para variar a rotação do ventilador e ajustar a vazão de ar aos valores de projeto, ou seja, $0,0138 \mathrm{~m}^{3} \mathrm{~min}^{-1}$ para o milho seco (11\%) e $0,0792 \mathrm{~m}^{3} \min ^{-1}$ para o milho úmido (17\%).

O monitoramento da temperatura dos grãos foi realizado com sensores digitais da marca Dallas, modelo DS18B20, com precisão de $\pm 0,5^{\circ} \mathrm{C}$ e resolução de $0,0625^{\circ} \mathrm{C}$. Os dados de 
temperatura foram armazenados em um sistema de aquisição de dados. O monitoramento das condições climáticas, temperatura e umidade relativa do ar foi realizado por um higrotermógrafo digital. Na automação da estratégia de aeração noturna, utilizou-se temporizador, e na estratégia de aeração em condições de equilíbrio higroscópico entre os grãos e o ar, foi utilizado um umidostato.

\section{Preparo da matéria-prima}

O teor de água de 17\% foi atingido umidificando-se os lotes de milho com adição de água e revolvimento frequente da massa por um período de quatro dias, em câmara com temperatura de $17^{\circ} \mathrm{C}$. A massa de água acrescentada foi calculada a partir dos valores de teor de água inicial e final (17\%) dos grãos. Embora a expressão "milho úmido" não seja a mais adequada em razão do procedimento utilizado, essa terminologia será utilizada no texto para facilitar sua identificação.

Os grãos foram aquecidos, visando a simular aquecimento espontâneo que pode ocorrer durante a armazenagem. Isto foi realizado com energia solar em sacos plásticos pretos, dispostos em camadas de $0,08 \mathrm{~m}$, com movimentação periódica (intervalos de 30 minutos a 60 minutos) e acompanhamento da temperatura até alcançarem $40{ }^{\circ} \mathrm{C}$.

\section{Procedimento experimental}

Foram realizados dois ensaios de aeração com duração de 24 dias. No primeiro ensaio, utilizaram-se lotes de milho seco e úmido, armazenados em seis silos: nos três primeiros (Silo 1, Silo 2 e Silo 3), estava o milho seco $(\mathrm{Ui}=11 \%)$ e, nos outros três (Silo 4, Silo 5 e Silo 6), o milho úmido $(\mathrm{Ui}=16,8 \%)$. Os testes com milho seco ocorreram no período de 12-8 a 4-9-2009 e, com milho úmido de 17-08 a 10-9-2009. O segundo ensaio foi realizado no período de 24-10 a 17-112009 apenas com milho seco (Ui=11,5\%), armazenado nos silos 1; 2 e 3. A este ensaio acrescentouse um silo-controle, sem aeração (Silo 0).

Os tratamentos de aeração foram: aeração contínua (Silos 1 e 4), aeração noturna (Silos 2 e 5) e aeração em condições de teor de água de equilíbrio higroscópico entre os grãos e o ar (Silos 3 e $6)$.

$\mathrm{Na}$ aeração contínua, o sistema operou ininterruptamente durante os 24 dias. Na aeração noturna, um temporizador realizava acionamento automático do ventilador, das 20 horas de um dia às 6 horas do dia seguinte. Na aeração em condições de equilíbrio, o sistema era acionado apenas quando a umidade relativa do ar ambiente estava em condições de equilíbrio higroscópico com o teor de água do grão; ou seja, para milho seco (11\%), o umidostato acionava o sistema de aeração na faixa de umidade relativa de $68 \%$ a $72 \%$, e na faixa de $83 \%$ a $87 \%$, para milho úmido (17\%).

\section{Análises}

Realizou-se monitoramento da temperatura dos grãos com sensores instalados nas seguintes alturas dos silos: $0,11 \mathrm{~m}, 0,33 \mathrm{~m}$ e $0,54 \mathrm{~m}$ acima da chapa perfurada. Em relação às seções transversais, três termopares foram posicionados próximos à parede do silo em pontos correspondentes aos vértices de um triângulo equilátero e um no centro, resultando em quatro termopares por altura e 12 termopares dentro do silo. Os dados de temperatura foram armazenados em intervalos de cinco minutos. A amostragem dos grãos foi realizada por calador, sendo utilizadas amostras de quatro janelas (quatro repetições) para a análise de teor de água. A determinação do teor de água foi realizada a cada três dias pelo método-padrão da estufa a $105 \pm 3{ }^{\circ} \mathrm{C}$, por 24 horas, em quadruplicata (BRASIL, 1992).

\section{Tratamento dos dados}

Utilizou-se o teste de Mann-Whitney, com nível de significância de 5\%, para a análise dos dados de temperatura, uma vez que os mesmos não apresentavam distribuição normal. Na análise de redução da temperatura ao longo do período de aeração, os dados foram separados em três grupos: grupo 1 (dois primeiros dias), grupo 2 (terceiro ao décimo terceiro dia) e grupo 3 (décimo quarto ao vigésimo quarto dia). O critério para a separação dos grupos foi baseado no comportamento da temperatura em relação ao tempo observado em teste preliminar. Dessa forma, compararam-se as 
medianas dos grupos 1 e 2 e dos grupos 1 e 3, a fim de verificar se houve redução significativa da temperatura. O teste de Estacionariedade de Kwiatkowski-Phillips-Schmidt-Shin (KPSS) foi aplicado aos dados de temperatura para avaliar se a distribuição dos dados foi homogênea após os dois primeiros dias de ensaio. O teste de Tukey foi utilizado para comparação de média dos dados de teor de água. Os testes estatísticos foram realizados com auxílio dos softwares Minitab, versão 15, e Assistat, versão 7.5 beta.

\section{RESULTADOS E DISCUSSÃO}

\section{Temperatura}

\section{Ensaio 1}

No primeiro ensaio, obtiveram-se os resultados da temperatura dos grãos de milho secos e úmidos submetidos à aeração, os quais são ilustrados nas Figuras 1 e 3 para cada uma das alturas da massa de grãos. Cada ponto da curva corresponde à média das temperaturas registradas nos quatro sensores instalados em cada altura. As condições meteorológicas, temperatura e umidade relativa ambiente, no período de realização do ensaio com milho seco, são apresentadas na Figura 2, e com milho úmido, na Figura 4.

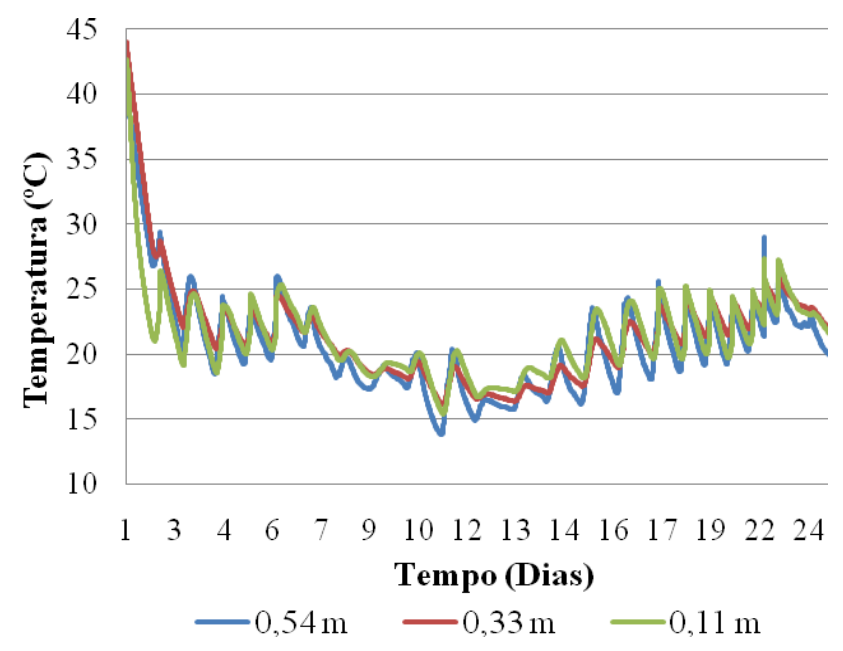

a - Silo 1
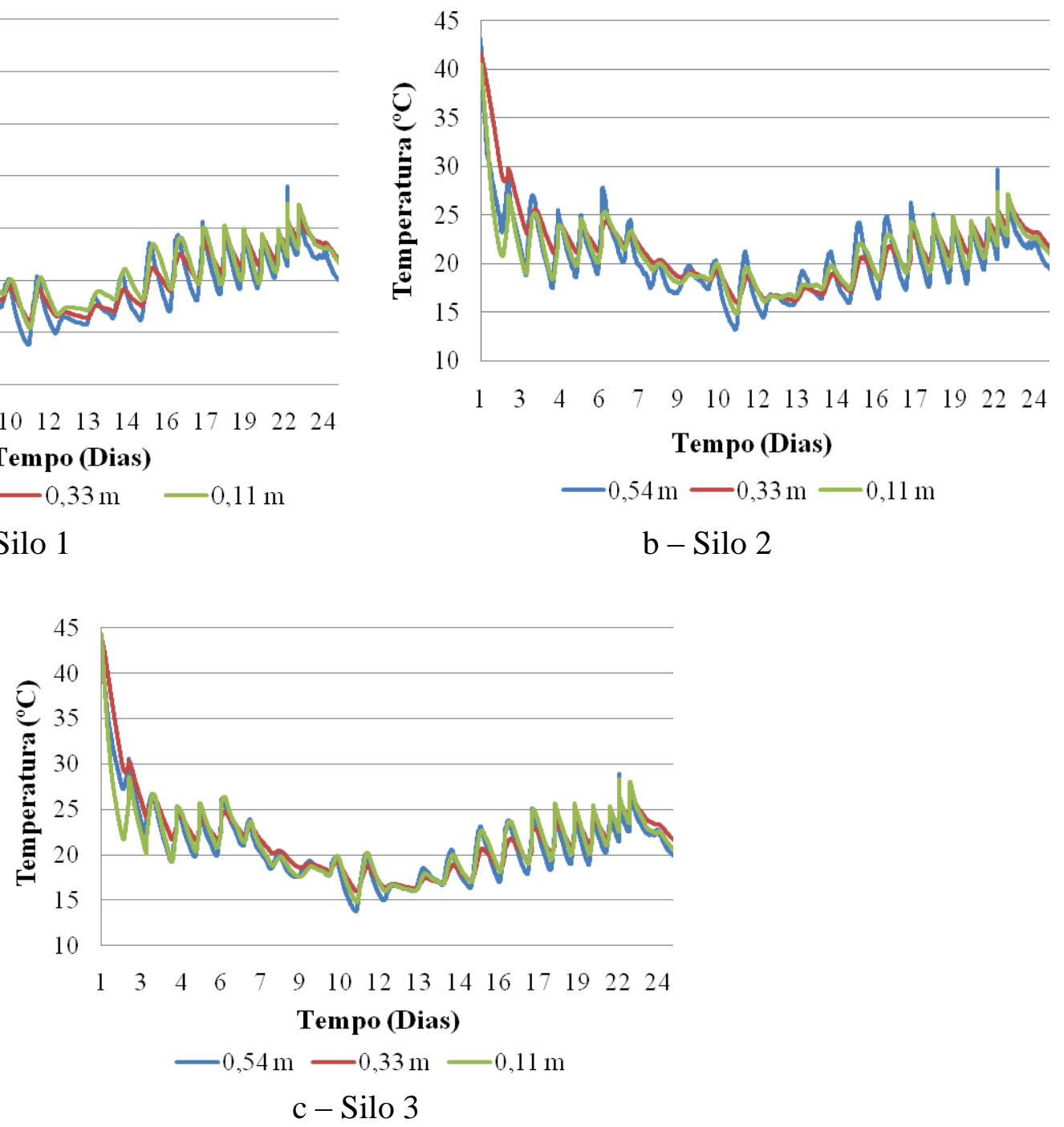

FIGURA 1. Comportamento da temperatura em três alturas da massa de grãos de milho seco (11\%.), armazenados durante 24 dias de aeração contínua (a), noturna (b) e em condições de equilíbrio higroscópico (c). Behavior of the temperature in three heights of the dry corn mass $(\mathbf{1 1 \%})$ stored for 24 days of continuous aeration (a), night (b) and under conditions of equilibrium moisture content (c). 


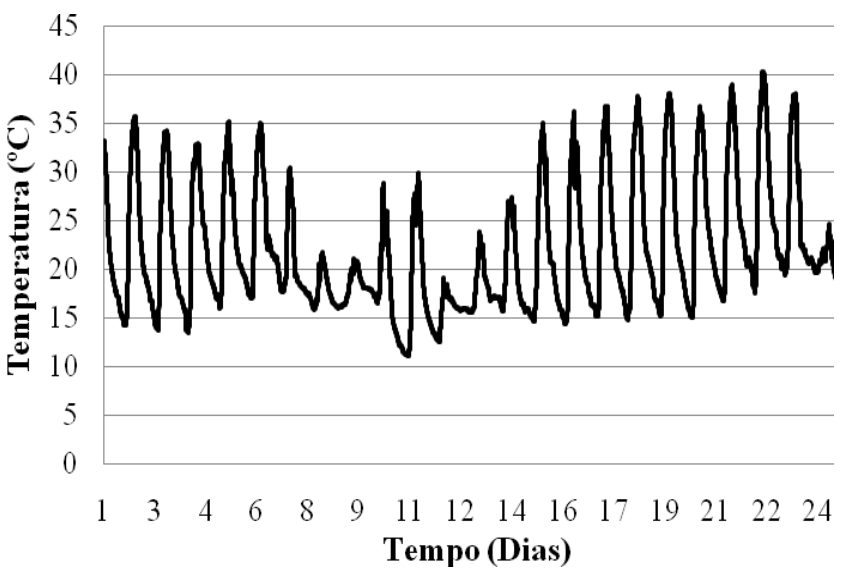

a - Temperatura Ambiente

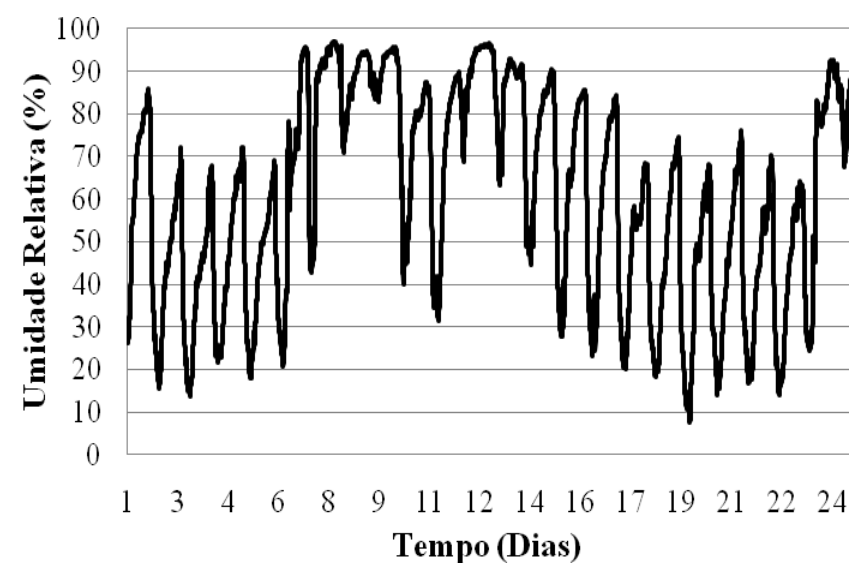

b - Umidade Relativa Ambiente

FIGURA 2. Gráficos de variação da temperatura (a) e umidade relativa do ar ambiente (b) durante o período de 12-8 a 5-9-2009 (Ensaio 1 - grãos secos). Graphs of temperature variation (a) and relative humidity of ambient air (b) from 8/12 to 9/5/2009 (Test 1 - dried grains).
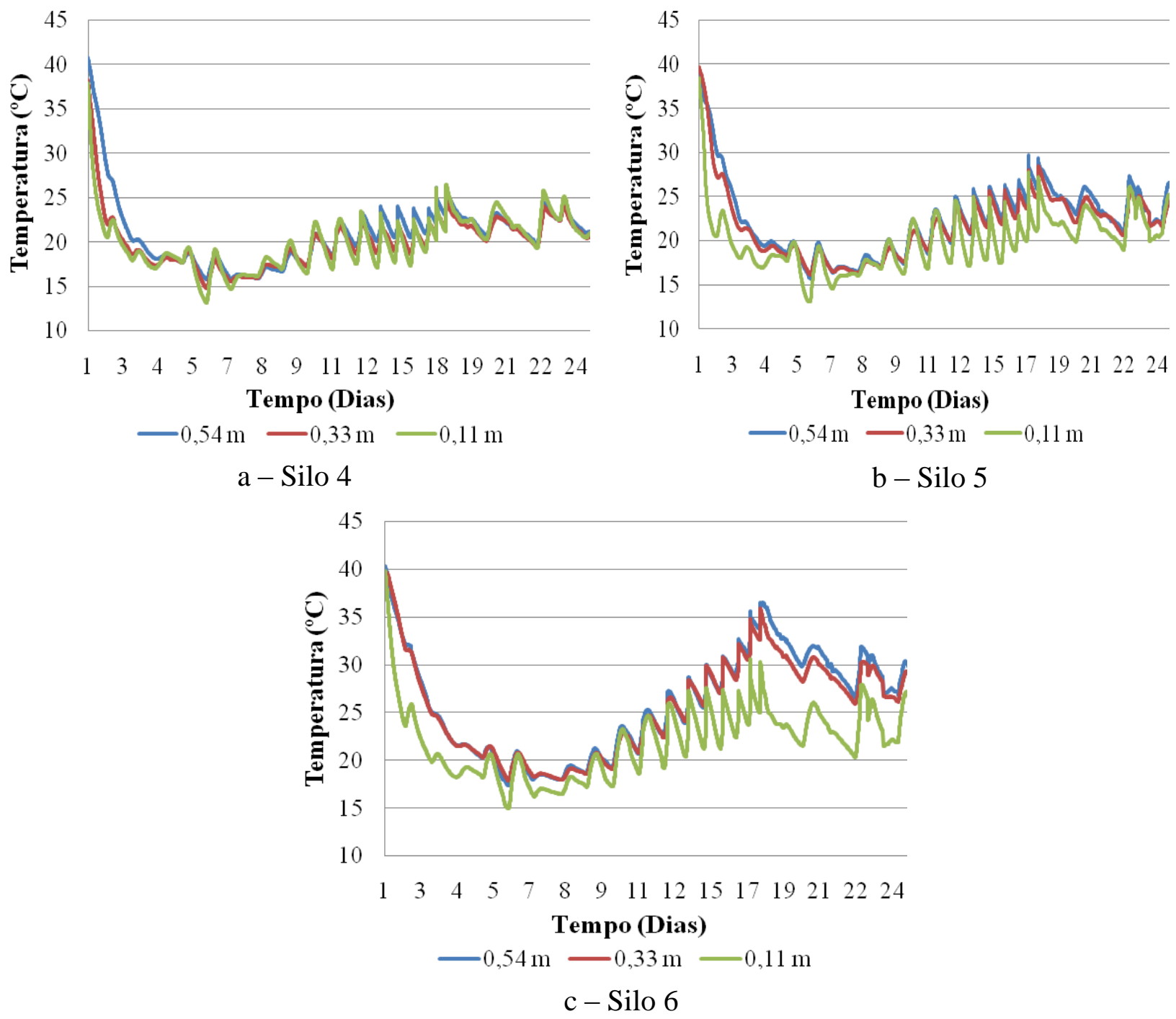

FIGURA 3. Comportamento da temperatura em três alturas da massa de grãos de milho úmido (16,8\%.), armazenados durante 24 dias de aeração contínua (a), noturna (b) e em condições de teor de água de equilíbrio higroscópico (c). Behavior of the temperature in three heights of the mass of moist corn grain (16.8\%) stored for 24 days of continuous aeration (a), night (b) and water content conditions of equilibrium moisture content (c). 


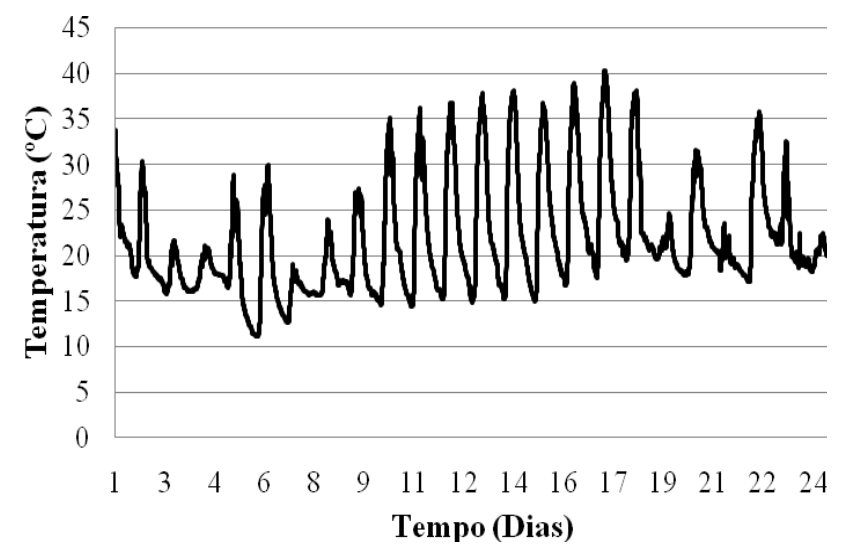

a-Temperatura Ambiente

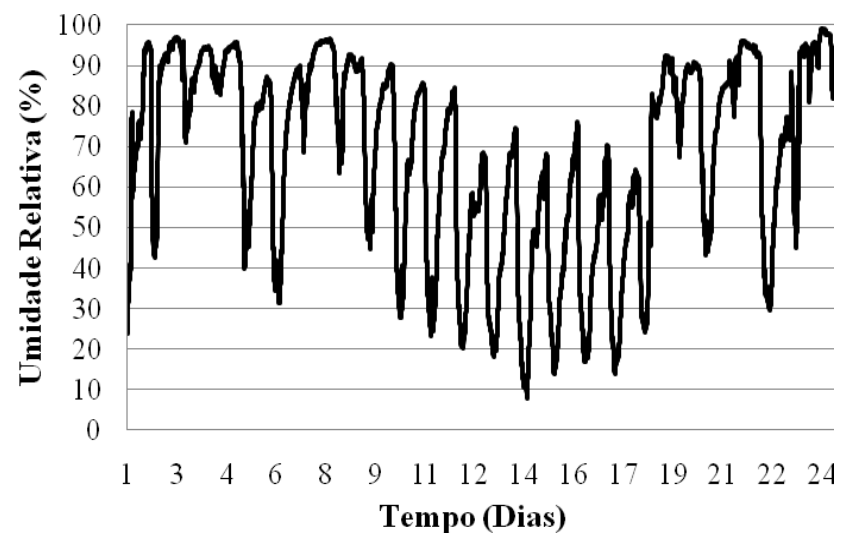

b - Umidade Relativa Ambiente

FIGURA 4. Gráficos de variação da temperatura (a) e umidade relativa do ar ambiente (b) durante o período de 17-8 a 10-9-2009 (Ensaio 1 - milho úmido). Graphs of temperature variation (a) and relative humidity of ambient air (b) from 8/17 to 10/9/2009 (Test 1 - wet corn).

Redução da temperatura ao longo do período de aeração

Observa-se pelas Tabelas 1 e 2 que a mediana do grupo 1 foi significativamente maior que a mediana dos grupos 2 e 3, o que permite afirmar que houve redução significativa da temperatura dos grãos ao longo do período de aeração em todos os tratamentos do ensaio 1, tanto em milho seco como em milho úmido.

TABELA 1. Mediana de temperatura de milho seco (11\%.) de diferentes intervalos de tempo durante aeração contínua (silo 1), noturna (silo 2) e em condições de equilíbrio higroscópico (silo 3) (Ensaio 1). Median temperature of dry corn (11\%) of different time intervals during continuous aeration (bin 1), night (bin 2) and under conditions of equilibrium moisture content (bin 3) (Test 1).

\begin{tabular}{ccccc} 
& Grupo & $0,54 \mathrm{~m}$ & $0,33 \mathrm{~m}$ & $0,11 \mathrm{~m}$ \\
\hline \multirow{3}{*}{ Silo 1 } & 1 & $27,47 \mathrm{a}$ & $27,83 \mathrm{a}$ & $23,35 \mathrm{a}$ \\
& 2 & $19,05 \mathrm{~b}$ & $19,66 \mathrm{~b}$ & $19,73 \mathrm{~b}$ \\
& 3 & $20,98 \mathrm{~b}$ & $21,96 \mathrm{~b}$ & $21,84 \mathrm{~b}$ \\
\hline \multirow{2}{*}{ Silo 2 } & 1 & $25,643 \mathrm{a}$ & $28,88 \mathrm{a}$ & $23,36 \mathrm{a}$ \\
& 2 & $18,99 \mathrm{~b}$ & $19,87 \mathrm{~b}$ & $19,43 \mathrm{~b}$ \\
& 3 & $20,78 \mathrm{~b}$ & $21,42 \mathrm{~b}$ & $21,25 \mathrm{~b}$ \\
\hline \multirow{2}{*}{ Silo 3 } & 1 & $28,37 \mathrm{a}$ & $29,69 \mathrm{a}$ & $24,85 \mathrm{a}$ \\
& 2 & $19,29 \mathrm{~b}$ & $19,93 \mathrm{~b}$ & $19,39 \mathrm{~b}$ \\
& 3 & $20,85 \mathrm{~b}$ & $21,53 \mathrm{~b}$ & $21,54 \mathrm{~b}$ \\
\hline
\end{tabular}

Médias seguidas pela mesma letra na coluna não diferem entre si, pelo teste de Tukey, a 5\% de probabilidade.

Observou-se que todas as estratégias de aeração promoveram redução de temperatura dos grãos nas primeiras 48 horas de ensaio. No entanto, em cada estratégia, valores diferentes de temperatura foram obtidos após dois dias de aeração. 
TABELA 2. Mediana de temperatura de milho úmido (16,8\%) de diferentes tempos da aeração contínua (silo 4), noturna (silo 5) e em condições de teor de água de equilíbrio higroscópico (silo 6) (Ensaio 1). Median temperature of wet corn (16.8\%) from different days of continuous aeration (bin 4), night (bin 5) and water content conditions of equilibrium moisture content (bin 6) (Test 1).

\begin{tabular}{lllll}
\hline & Grupo & $0,54 \mathrm{~m}$ & $0,33 \mathrm{~m}$ & $0,11 \mathrm{~m}$ \\
\hline \multirow{3}{*}{ Silo 4 } & 1 & $26,70 \mathrm{a}$ & $22,08 \mathrm{a}$ & $21,01 \mathrm{a}$ \\
& 2 & $18,20 \mathrm{~b}$ & $17,93 \mathrm{~b}$ & $17,89 \mathrm{~b}$ \\
& 3 & $22,17 \mathrm{~b}$ & $21,42 \mathrm{~b}$ & $21,59 \mathrm{~b}$ \\
\hline \multirow{2}{*}{ Silo 5 } & 1 & $29,34 \mathrm{a}$ & $27,20 \mathrm{a}$ & $21,11 \mathrm{a}$ \\
& 2 & $19,20 \mathrm{~b}$ & $18,84 \mathrm{~b}$ & $17,75 \mathrm{~b}$ \\
& 3 & $24,44 \mathrm{~b}$ & $23,62 \mathrm{~b}$ & $21,45 \mathrm{~b}$ \\
\hline \multirow{2}{*}{ Silo 6 } & 1 & $31,75 \mathrm{a}$ & $31,44 \mathrm{a}$ & $24,31 \mathrm{a}$ \\
& 2 & $20,81 \mathrm{~b}$ & $20,75 \mathrm{~b}$ & $18,92 \mathrm{~b}$ \\
& 3 & $29,92 \mathrm{~b}$ & $29,06 \mathrm{~b}$ & $23,87 \mathrm{~b}$ \\
\hline
\end{tabular}

Médias seguidas pela mesma letra na coluna não diferem entre si, pelo teste de Tukey, a 5\% de probabilidade.

Na Tabela 3, são apresentados os dados de temperatura inicial, da temperatura observada após 48 horas de aeração e os valores de redução da temperatura (temperatura inicial menos a observada após 48 horas) observada em cada silo nesse período. A partir dessa tabela, é possível observar que, em milho seco (silos 1; 2 e 3), as estratégias de aeração contínua (silo 1) e em condições de equilíbrio higroscópico entre os grãos e o ar (silo 3) obtiveram redução de temperatura maior que a estratégia de aeração noturna (silo 2). Em relação à aeração de milho úmido (silos 4; 5 e 6), a estratégia que apresentou melhor desempenho foi a aeração contínua (silo 1), enquanto a aeração noturna (silo 2) obteve desempenho intermediário, e a de menor eficiência foi a aeração em condições de equilíbrio higroscópico (silo 3).

TABELA 3. Dados da temperatura inicial, após 48 horas de aeração e redução de temperatura nas estratégias de aeração contínua (silos 1 e 4), noturna (silos 2 e 5) e em condições de equilíbrio higroscópico (silo 3 e 6) de milho seco (silos $1 ; 2$ e 3 ) e úmido (silos $4 ; 5$ e 6). Data from the initial temperature, after $\mathbf{4 8}$ hours of aeration and temperature reduction strategies for continuous aeration (bins 1 and 4) night (bins 2 and 5) and under conditions of equilibrium moisture content (bins 3 and 6 ) dry corn (bins 1, 2 and 3) and wet (bins 4, 5 and 6).

\begin{tabular}{cccc}
\hline Silos & Início & 48 horas & Redução de Temperatura \\
\hline 1 & 42,58 & 24,20 & 18,38 \\
2 & 41,79 & 24,79 & 17,00 \\
3 & 44,07 & 25,64 & 18,43 \\
4 & 38,19 & 19,10 & 19,09 \\
5 & 38,96 & 21,43 & 17,53 \\
6 & 39,78 & 24,64 & 15,14 \\
\hline
\end{tabular}

Homogeneidade da temperatura após 48 horas de aeração

Aplicando-se o teste de KPSS aos dados de temperatura após 48 horas de início do ensaio para avaliar a homogeneidade do seu comportamento no tempo, verificou-se, em todos os testes, que o p-valor foi menor que 0,05 , isto é, têm-se evidências suficientes para rejeitar a hipótese de que os dados de temperatura sejam homogêneos. Desta forma, pode-se concluir que a temperatura não se manteve homogênea ao longo dos dias. Esse resultado foi obtido no ensaio $1 \mathrm{com}$ milho seco e úmido. 
Observando-se os gráficos do comportamento da temperatura nos 24 dias de aeração nos silos 1; 2 e 3 (Figura 1), e comparando-os visualmente com a Figura 2, que corresponde à curva de variação da temperatura do ar ambiente, é possível perceber que, depois do segundo dia de ensaio, a temperatura no interior da massa de grãos de milho seco variou de acordo com as condições climáticas, concordando com o resultado obtido no teste de KPSS. O mesmo comportamento foi observado no ensaio com milho úmido (Figuras 3 e 4 ).

Quando se observou o comportamento da temperatura dos silos com milho úmido, percebeu-se que, a partir do $7^{\circ}$ dia, a temperatura dos grãos de todos os silos começou a se elevar e, no $18^{\circ}$ dia, atingiu o ponto máximo. Na Figura 3, nota-se claramente que o aumento da temperatura foi mais acentuado nos silos 5 e 6 , destacando-se as alturas de $0,54 \mathrm{~m}$ e 0,33 m. Pode-se atribuir esse resultado ao tempo de aeração empregado nas diferentes estratégias, considerando-se que a elevação de temperatura teve uma relação inversa ao tempo de aeração. Na aeração contínua, o sistema permaneceu ligado durante todo o ensaio, ou seja, 576 horas; na aeração noturna, o tempo de processo foi de 240 horas e, na aeração em condições de equilíbrio higroscópico o sistema ficou ligado 48 horas e 57 minutos. Esse resultado concorda com SILVA (2000), que afirma que a aeração contínua previne o aquecimento dos grãos úmidos enquanto é aguardada a operação de secagem.

De acordo com BENEDETTI (1992), variações da temperatura em grãos armazenados são devidas a fontes de calor interna e externa ao sistema. As fontes internas são originárias da respiração do produto e da ação de insetos e microrganismos, enquanto a temperatura ambiente e a radiação solar são as fontes externas.

Durante o período de armazenamento, nos silos 5 e 6 , o produto aqueceu-se até o $18^{\circ}$ dia, depois a temperatura no interior da massa de grãos decresceu até o final dos testes (Figura 3).

Analisando-se o comportamento da temperatura do silo 6 individualmente, com auxílio dos dados de temperatura e umidade relativa ambiente registrados pelo higrotermógrafo, observou-se que, no período entre o $12^{\circ}$ e o $17^{\circ}$ dia, a temperatura do ar ambiente estava elevada (mínima de $15^{\circ} \mathrm{C}$; máxima de $40{ }^{\circ} \mathrm{C}$ ), e a umidade relativa, baixa (mínima de $10 \%$; máxima de $75 \%$ ). Lembrando que a faixa de umidade relativa do ar ambiente de acionamento do sistema de aeração era de $83 \%$ a $87 \%$; registra-se que, durante esse período, o sistema de aeração ficou desligado. Assim, infere-se que o alto teor de água dos grãos de milho, aliado à ausência de operação do sistema de aeração, no período de cinco dias, possibilitou o desenvolvimento de fungos, cujo metabolismo causou a elevação da temperatura no interior da massa de grãos. As camadas mais afetadas pela elevação da temperatura e consequente desenvolvimento de fungos corresponderam às alturas de $0,54 \mathrm{~m}$ e $0,33 \mathrm{~m}$. A redução de temperatura que ocorreu do $19^{\circ}$ dia até o final do ensaio foi produto de alterações climáticas, uma vez que, a partir desse dia, a umidade do ar aumentou, acionando assim o sistema de aeração por mais $16 \mathrm{~h} 27 \mathrm{~min}$ e provocando o resfriamento da massa de grãos.

\section{Ensaio 2}

No segundo ensaio, obtiveram-se os resultados de temperatura em grãos de milho secos submetidos à aeração, apresentados na Figura 5. As condições meteorológicas, temperatura e umidade relativa ambiente, no período de realização do ensaio, são apresentadas na Figura 6. 

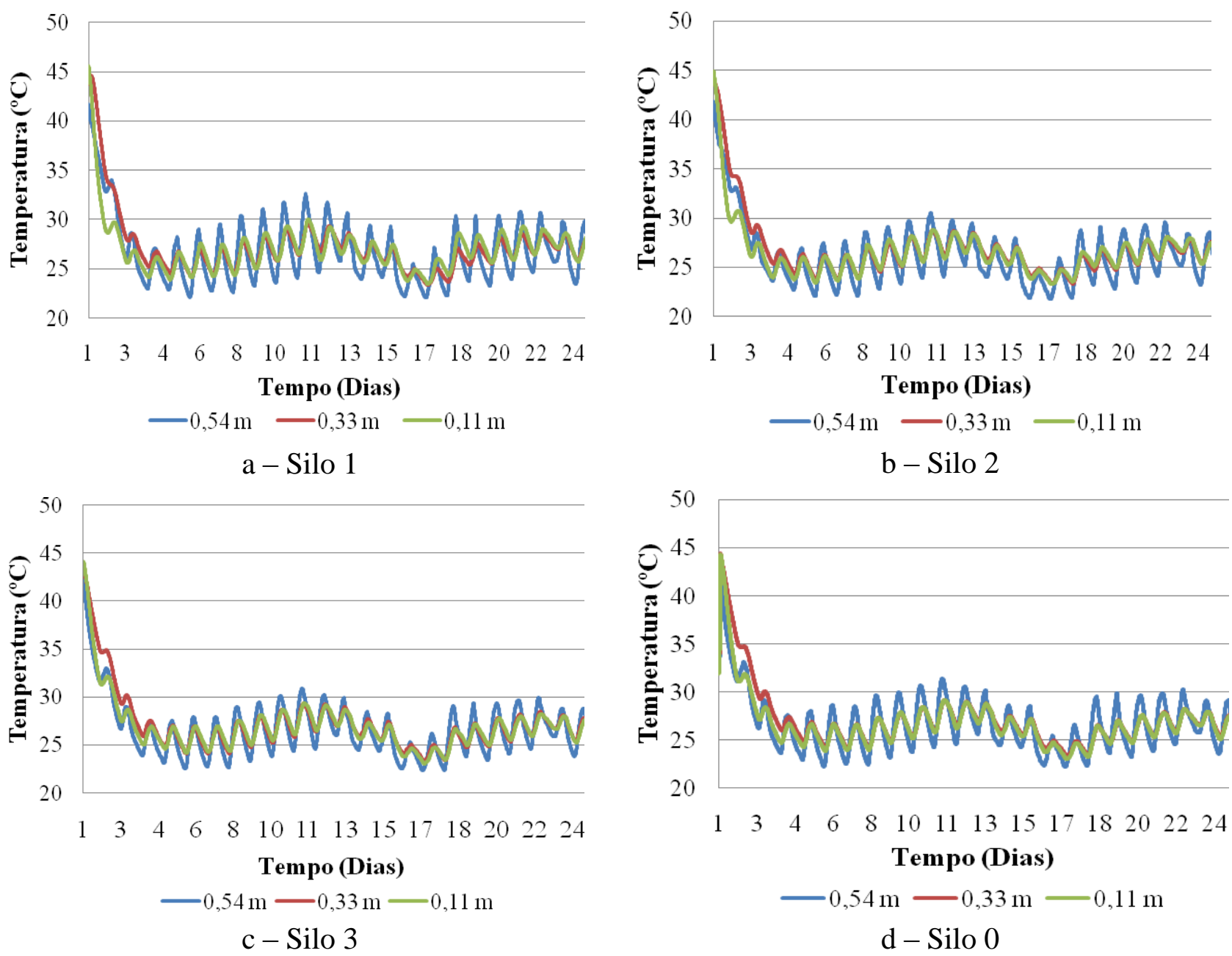

FIGURA 5. Comportamento da temperatura em três alturas da massa de grãos de milho seco (11,5\%), armazenados durante 24 dias de aeração contínua (a), noturna (b), em condições de equilíbrio higroscópico (c) e no silo-controle (d). Behavior of the temperature in three heights of dry corn mass $(\mathbf{1 1 . 5 \%})$ stored for 24 days of continuous aeration (a), night (b) under conditions of equilibrium moisture content (c) in the control bin (d).
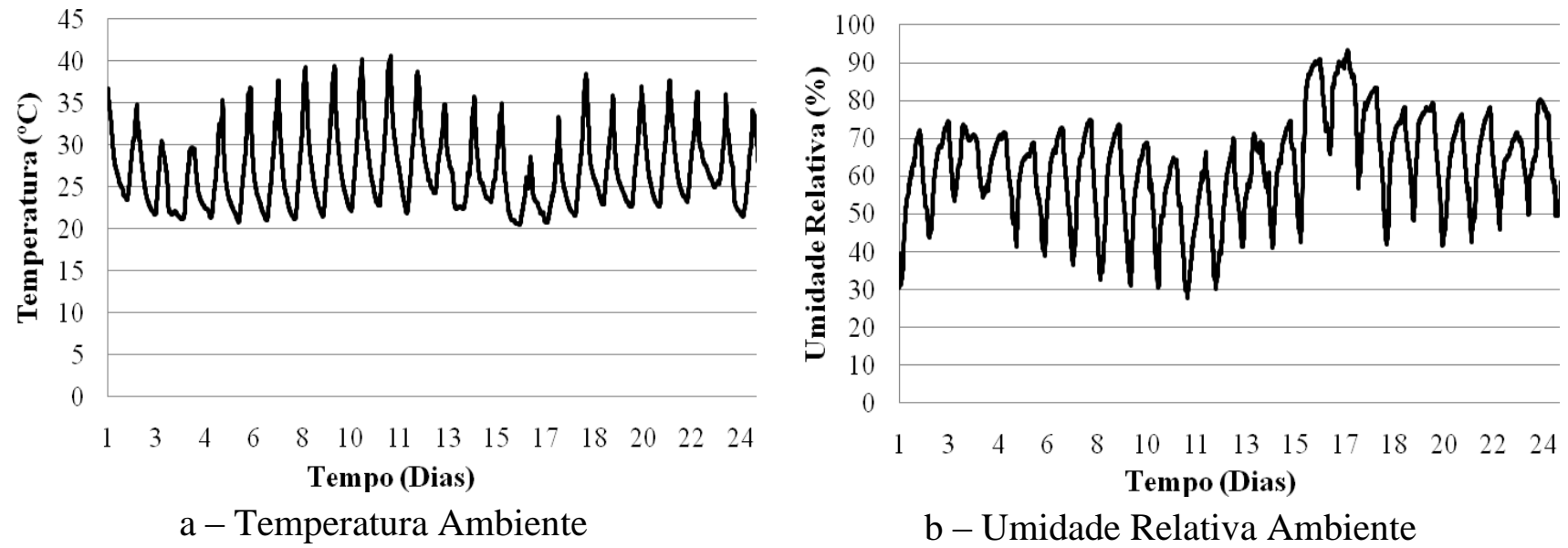

FIGURA 6. Gráfico de variação da temperatura (a) e umidade relativa do ar ambiente (b) durante o período de 27-10 a 17-11-2009 (Ensaio 2 - milho seco). Graph of temperature variation (a) and relative humidity of ambient air (b) from 10/27 to 11/17/2009 (Test 2 - dried corn). 
Redução da temperatura ao longo do período de aeração

Verifica-se, na Tabela 4, que a mediana do grupo 1 foi significativamente maior que a mediana dos grupos 2 e 3, o que permite afirmar que houve redução significativa da temperatura dos grãos em todos os tratamentos com grãos secos do ensaio 2.

TABELA 4. Mediana dos dados de temperatura dos grupos 1; 2 e 3 das estratégias de aeração contínua (silo 1), noturna (silo 2), em condições de equilíbrio higroscópico (silo 3) e do silo-controle (0) do ensaio 2. Median temperature data of groups 1, 2 and 3 of the continuous aeration strategies (bin 3), night (bin 2), under conditions of equilibrium moisture content (bin 3) and control bin (0) of test 2.

\begin{tabular}{cclll}
\hline & Grupo & $0,54 \mathrm{~m}$ & $0,33 \mathrm{~m}$ & $0,11 \mathrm{~m}$ \\
\hline \multirow{3}{*}{ Silo 1 } & 1 & $33,17 \mathrm{a}$ & $33,54 \mathrm{a}$ & $29,31 \mathrm{a}$ \\
& 2 & $26,12 \mathrm{~b}$ & $26,62 \mathrm{~b}$ & $26,49 \mathrm{~b}$ \\
& 3 & $25,76 \mathrm{~b}$ & $26,53 \mathrm{~b}$ & $26,76 \mathrm{~b}$ \\
\hline \multirow{2}{*}{ Silo 2 } & 1 & $32,86 \mathrm{a}$ & $34,25 \mathrm{a}$ & $30,23 \mathrm{a}$ \\
& 2 & $25,57 \mathrm{~b}$ & $26,17 \mathrm{~b}$ & $25,91 \mathrm{~b}$ \\
& 3 & $25,23 \mathrm{~b}$ & $26,06 \mathrm{~b}$ & $26,11 \mathrm{~b}$ \\
\hline \multirow{2}{*}{ Silo 3 } & 1 & $32,18 \mathrm{a}$ & $34,71 \mathrm{a}$ & $31,76 \mathrm{a}$ \\
& 2 & $26,14 \mathrm{~b}$ & $26,65 \mathrm{~b}$ & $26,59 \mathrm{~b}$ \\
& 3 & $25,81 \mathrm{~b}$ & $26,25 \mathrm{~b}$ & $26,20 \mathrm{~b}$ \\
\hline \multirow{2}{*}{ Silo 0 } & 1 & $31,84 \mathrm{a}$ & $34,71 \mathrm{a}$ & $31,47 \mathrm{a}$ \\
& 2 & $26,22 \mathrm{~b}$ & $26,56 \mathrm{~b}$ & $26,29 \mathrm{~b}$ \\
& 3 & $25,81 \mathrm{~b}$ & $26,15 \mathrm{~b}$ & $26,03 \mathrm{~b}$ \\
\hline
\end{tabular}

Médias seguidas pela mesma letra na coluna não diferem entre si, pelo teste de Tukey, a 5\% de probabilidade.

Todos os tratamentos permitiram a redução da temperatura dos grãos nos dois primeiros dias de aeração. Todavia, pode-se observar, na Tabela 5, que a aeração contínua obteve maior redução de temperatura que as demais. Ao contrário do ensaio 1 com milho seco, a estratégia de aeração em condições de equilíbrio higroscópico apresentou o menor valor de redução de temperatura.

TABELA 5. Temperatura inicial, após 48 horas de aeração e redução de temperatura da aeração contínua (silo 1), noturna (silo 2), em condições de equilíbrio higroscópico (silo 3), e do silo-controle (0) em milho seco. Initial temperature, after 48 hours of aeration and temperature reduction of continuous aeration (bin 1), night (bin 2), under conditions of equilibrium moisture content (bin 3 ) and the control bin (0) in dry corn.

\begin{tabular}{cccc}
\hline Silos & Início & 48 horas & Redução de Temperatura \\
\hline 1 & 43,76 & 28,40 & 15,36 \\
2 & 43,56 & 28,42 & 15,14 \\
3 & 43,59 & 28,98 & 14,61 \\
0 & 44,31 & 29,12 & 15,19 \\
\hline
\end{tabular}

Homogeneidade da temperatura após 48 horas de aeração

No ensaio 2, verificou-se o mesmo comportamento da temperatura observado no ensaio 1 com milho seco. A temperatura no interior dos grãos variou conforme as condições climáticas e, portanto, não se manteve homogênea ao longo do ensaio (Figuras 5 e 6). 


\section{Teor de água}

\section{Ensaio 1}

\section{Comparação do teor de água dos grãos entre camadas}

Na Tabela 6, observa-se que o teor de água médio durante o ensaio dos silos 1 e 2 manteve-se uniforme entre as camadas em 0,54 m, 0,33 m e 0,11 m. Nos silos 3; 4 e 5, verificou-se diferença do teor de água entre as alturas de $0,54 \mathrm{~m}$ e $0,11 \mathrm{~m}$, sendo que os grãos da altura de $0,11 \mathrm{~m}$ apresentaram menor teor de água. Em relação ao silo 6, o teor de água da altura de 0,11 m foi menor que o das camadas superior e intermediária. Esses resultados demonstram que, principalmente nos grãos aerados úmidos, a camada mais próxima da entrada de ar $(0,11 \mathrm{~m})$ favoreceu a redução do teor de água.

TABELA 6. Teor de água em três alturas dos silos de aeração contínua (1 e 4), noturna (2 e 5) e em condições de equilíbrio higroscópico (3 e 6) de milho seco (silos 1; 2 e 3 ) e úmido (silos 4; 5 e 6 ) do ensaio 1 . Water content in three heights of continuous aeration bins ( 1 and 4), Night ( 2 and 5 ) and under conditions of equilibrium moisture content ( 3 and 6 ) dry corn (bins 1, 2 and 3 ) and wet (bins 4, 5 and 6 ) of test 1.

\begin{tabular}{cccccccc}
\hline & & Silo 1 & Silo 2 & Silo 3 & Silo 4 & Silo 5 & Silo 6 \\
\hline \multirow{3}{*}{$0,54 \mathrm{~m}$} & Média & $11,64 \mathrm{a}$ & $11,38 \mathrm{a}$ & $12,29 \mathrm{a}$ & $16,41 \mathrm{a}$ & $16,78 \mathrm{a}$ & $16,09 \mathrm{a}$ \\
& DP & 1,20 & 1,47 & 1,22 & 1,22 & 1,25 & 1,04 \\
& C.V. & 10,32 & 12,89 & 10,24 & 7,41 & 7,43 & 6,45 \\
\hline \multirow{3}{*}{$0,33 \mathrm{~m}$} & Média & $10,91 \mathrm{a}$ & $11,27 \mathrm{a}$ & $11,66 \mathrm{ab}$ & $15,83 \mathrm{ab}$ & $15,87 \mathrm{ab}$ & $16,77 \mathrm{a}$ \\
& DP & 0,71 & 0,87 & 0,79 & 1,18 & 0,56 & 0,70 \\
& C.V. & 6,52 & 7,76 & 6,84 & 7,47 & 3,52 & 4,17 \\
\hline \multirow{3}{*}{$0,11 \mathrm{~m}$} & Média & $10,71 \mathrm{a}$ & $10,87 \mathrm{a}$ & $11,05 \mathrm{~b}$ & $14,26 \mathrm{~b}$ & $15,18 \mathrm{~b}$ & $15,10 \mathrm{~b}$ \\
& DP & 1,10 & 1,04 & 1,01 & 0,75 & 1,46 & 0,75 \\
& C.V. & 10,24 & 9,59 & 9,29 & 4,95 & 9,60 & 4,95 \\
\hline
\end{tabular}

Médias seguidas pela mesma letra na coluna não diferem entre si, pelo teste de Tukey, a 5\% de probabilidade.

\section{Efeito da estratégia de aeração}

Analisando-se a Figura 7, observa-se que o teor de água dos grãos secos na primeira semana manteve-se constante, mas elevou-se no nono e no décimo quinto dia do ensaio. Esse reumedecimento ocorreu devido às condições meteorológicas, de alta umidade relativa e baixa temperatura do ar ambiente (Figura 2). A partir do décimo oitavo dia, o teor de água foi reduzido novamente até valores inferiores ao inicial. De modo geral, verificou-se, durante o armazenamento, a tendência de redução do teor de água desses grãos.

CASADA et al. (2002) observaram reumedecimento de grãos armazenados, devido à umidade relativa elevada durante o período noturno.

No caso dos grãos armazenados úmidos, até cerca da metade do período de aeração, o teor de água foi reduzindo-se gradativamente, e do décimo segundo ao décimo quinto dia, observou-se uma redução mais significativa do mesmo $(2,5 \%)$. Em seguida, apresentou crescimento, mas ao final do período de aeração atingiu teor de água abaixo do inicial. Quando se observa o comportamento da temperatura no décimo quinto dia de ensaio (Figura 3), verifica-se que foi justamente um dos dias mais quentes no interior dos silos, principalmente no tratamento de aeração em condições de equilíbrio higroscópico entre os grãos e o ar. Portanto, atribui-se essa redução do teor de água à elevação de temperatura na massa de grãos.

$\mathrm{O}$ aumento da temperatura mencionado acima, aliado ao elevado teor de água inicial dos grãos, provocou desenvolvimento de fungos, que por sua vez está relacionado com a redução do teor de água do produto (MERONUCK, 1987, citado por RIBEIRO et al., 2003). 
Realizando-se comparação do teor de água médio do ensaio entre as estratégias de aeração não se obteve diferença significativa entre esses teores, tanto em milho seco (silos 1;2 e 3) como em milho umidificado (silos 4; 5 e 6), como pode ser observado pela Tabela 7.

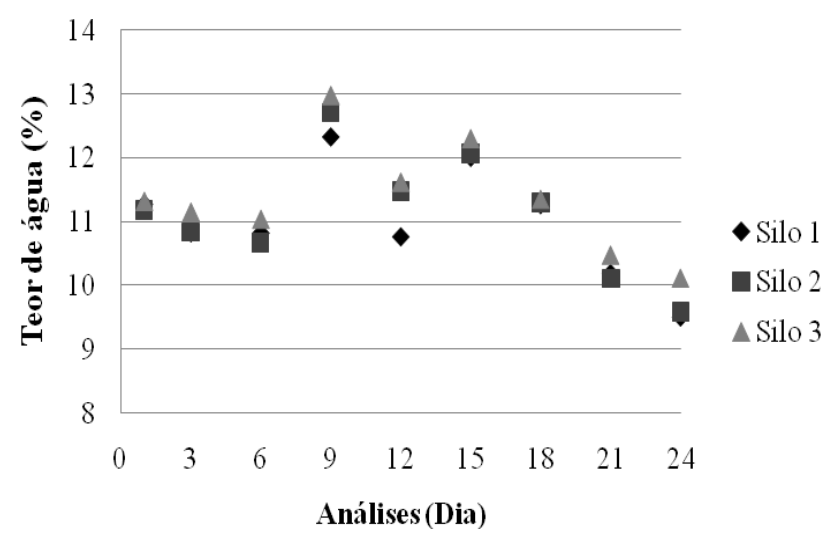

(a) Milho seco

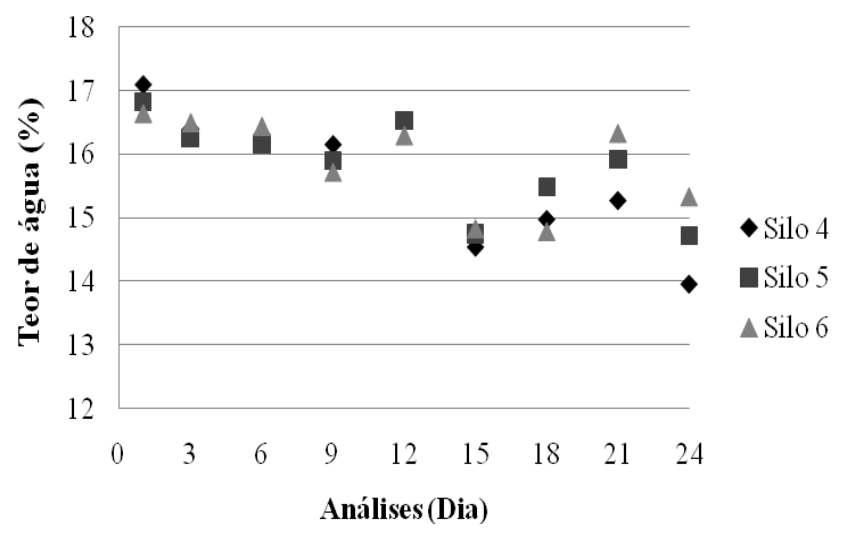

(b) Milho úmido

FIGURA 7. Variação do teor de água dos grãos nos silos de aeração contínua (1 e 4), noturna (2 e 5) e em condições de equilíbrio higroscópico (3 e 6) de milho seco (a) e úmido (b) do ensaio 1. Variation in moisture content of grain in the bins of continuous aeration ( 1 and 4), night ( 2 and 5) and under conditions of equilibrium moisture content ( 3 and 6$)$ of dry corn (a) and wet corn (b) of test 1.

TABELA 7. Teor de água dos grãos entre aeração contínua (1 e 4), noturna (2 e 5) e em condições de equilíbrio higroscópico (3 e 6), em milho seco (1;2 e 3) e úmido (4; 5 e 6) do ensaio 1. Water content of grains between continuous aeration ( 1 and 4$)$, Night ( 2 and 5) and under conditions of equilibrium moisture content ( 3 and 6 ), in dry corn $(1,2$ and 3$)$ and wet corn $(4,5$ and 6$)$ of test 1 .

\begin{tabular}{cccc}
\hline Silos & Média & Silos & Média \\
\hline 1 & $11,09 \mathrm{a}$ & 4 & $15,50 \mathrm{a}$ \\
2 & $11,17 \mathrm{a}$ & 5 & $15,94 \mathrm{a}$ \\
3 & $11,47 \mathrm{a}$ & 6 & $15,99 \mathrm{a}$ \\
\hline
\end{tabular}

Médias seguidas pela mesma letra na coluna não diferem entre si, pelo teste de Tukey, a 5\% de probabilidade.

\section{Comparação do teor de água dos grãos entre camadas}

Nos silos 1 e 2, observou-se que a altura inferior $(0,11 \mathrm{~m})$ apresentou teor de água diferente das alturas superior $(0,54 \mathrm{~m})$ e intermediária $(0,33 \mathrm{~m})$, sendo esse valor menor na altura de $0,11 \mathrm{~m}$. No silo 3, a altura de $0,33 \mathrm{~m}$ apresentou-se com menor teor de água e, no silo-controle (0), houve heterogeneidade entre as alturas de $0,11 \mathrm{~m}, 0,33 \mathrm{~m}$ e $0,54 \mathrm{~m}$, pois todos os teores de água diferiram entre si, e a altura de $0,11 \mathrm{~m}$ foi a que apresentou menor teor de água (Tabela 8). 
TABELA 8. Teor de água dos grãos em três alturas dos silos de aeração contínua (1), noturna (2), condições de equilíbrio higroscópico (3) e controle (0) (Ensaio 2 - milho seco). Moisture content of grain in three heights of the bins of continuous aeration (1), night (2), conditions of equilibrium moisture content (3) and control (0) (Test 2 dried corn).

\begin{tabular}{rcccccc}
\hline & & Silo 1 & Silo 2 & Silo 3 & Silo 0 \\
\hline \multirow{3}{*}{$0,54 \mathrm{~m}$} & Média & $11,53 \mathrm{a}$ & $11,66 \mathrm{a}$ & $11,57 \mathrm{a}$ & $11,88 \mathrm{a}$ & \\
& DP & 0,46 & 0,34 & 0,31 & 0,41 & \\
& C.V. & 4,00 & 2,89 & 2,70 & 3,45 & \\
\hline \multirow{3}{*}{$0,33 \mathrm{~m}$} & Média & $11,00 \mathrm{a}$ & $11,45 \mathrm{a}$ & $11,12 \mathrm{~b}$ & $11,21 \mathrm{~b}$ \\
& DP & 0,45 & 0,29 & 0,29 & 0,28 & \\
& C.V. & 4,06 & 2,54 & 2,61 & 2,53 & \\
\hline \multirow{3}{*}{$0,11 \mathrm{~m}$} & Média & $10,39 \mathrm{~b}$ & $10,44 \mathrm{~b}$ & $11,83 \mathrm{a}$ & 10,72 & $\mathrm{c}$ \\
& DP & 0,59 & 0,40 & 0,11 & 0,36 & \\
& C.V. & 5,70 & 3,86 & 0,96 & 3,31 & \\
\hline
\end{tabular}

Médias seguidas pela mesma letra na coluna não diferem entre si, pelo teste de Tukey, a 5\% de probabilidade.

Efeito da estratégia de aeração

No ensaio 2, observou-se pequena variação do teor de água dos grãos armazenados. Essa observação foi comum em todos os tratamentos de aeração. No entanto, percebeu-se que o silo 1 (aeração contínua) apresentou, durante todo o ensaio, teores de água mais baixos que os demais, o que pode ser observado na Figura 8 e nos resultados da análise estatística (Tabela 9).

TABELA 9. Comparação do teor de água dos grãos entre as estratégias de aeração contínua (1), noturna (2), em condições de equilíbrio higroscópico (3) e do silo controle (0) em milho seco do ensaio 2. Comparison of the moisture content of grain between the continuous aeration strategies (1), night (2) under conditions of equilibrium moisture content (3) and the control bin (0) in dry corn in test 2.

\begin{tabular}{cl}
\hline Silos & Médias \\
\hline 1 & $10,97 \mathrm{~b}$ \\
2 & $11,18 \mathrm{ab}$ \\
3 & $11,50 \mathrm{a}$ \\
0 & $11,27 \mathrm{ab}$ \\
\hline
\end{tabular}

Médias seguidas pela mesma letra na coluna não diferem entre si pelo teste de Tukey a 5\% de probabilidade.

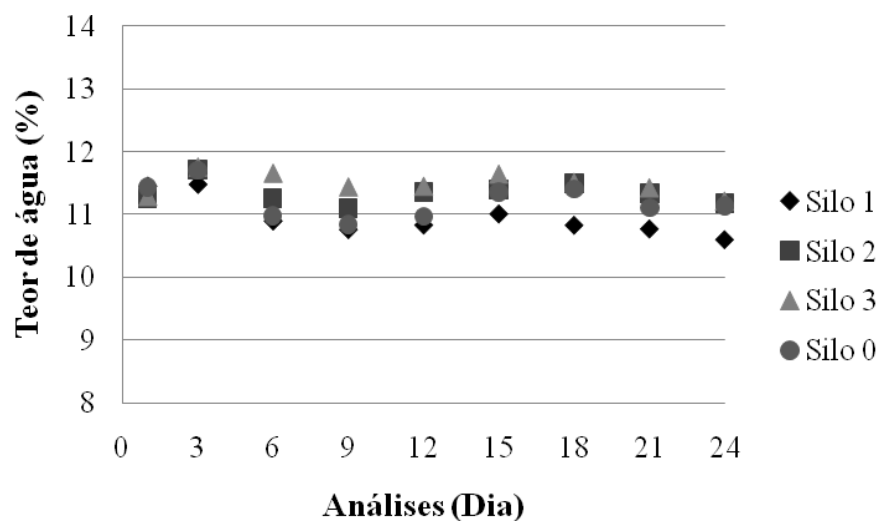

FIGURA 8. Variação do teor de água dos grãos nos silos de aeração contínua (1), noturna (2) e nas condições de equilíbrio higroscópico (3) e sem aeração (0) com milho seco do ensaio 2. Variation in moisture content of grain in bins of continuous aeration (1), night (2) and under the conditions of equilibrium moisture content (3) and without aeration (0) with dry corn in test 2. 


\section{CONCLUSÕES}

Todas as estratégias de aeração promoveram redução de temperatura nos primeiros dois dias, tanto no ensaio 1 como no 2. Entretanto, a aeração em condições de equilíbrio higroscópico entre os grãos e o ar foi a de melhor desempenho em grãos secos do ensaio 1, enquanto em grãos umidificados do ensaio 1 e em grãos secos do ensaio 2 a melhor estratégia foi a aeração contínua.

Depois do período de resfriamento inicial, não se verificou homogeneidade da temperatura nos silos aerados e no controle.

A aeração contínua foi eficiente na prevenção do aquecimento de grãos umidificados e na conservação da qualidade desses grãos.

O teor de água dos grãos sofreu variação durante os ensaios realizados. No ensaio 1, as estratégias de aeração contínua e noturna foram favoráveis à manutenção da uniformidade do teor de água médio entre as alturas dos silos com grãos secos; já nos grãos armazenados umidificados verificou-se secagem na altura de $0,11 \mathrm{~m}$, próxima à entrada de ar. No ensaio 2 , as estratégias de aeração contínua, noturna e o controle apresentaram menores valores de teor de água na altura de $0,11 \mathrm{~m}$.

As estratégias de aeração não interferiram no teor de água médio dos grãos armazenados secos e umidificados do ensaio 1 . No ensaio 2, a estratégia de aeração contínua promoveu secagem dos grãos.

\section{AGRADECIMENTOS} estudos.

À CPG/FEAGRI, à FAEPEX e à FAPESP, pelo financiamento. Ao CNPq, pela bolsa de

\section{REFERÊNCIAS}

BENEDETTI, B.C. Investigation into the processes of heat and moisture transfer in stored maize. 1992. 266f. Thesis (PhD. In Agricultural Engineering) - Cranfield Institute of Technology, Silsoe, 1992.

BRASIL. MINISTÉRIO DA AGRICULTURA E REFORMA AGRÁRIA. Regras para análise de sementes. Brasília, 1992.

CASADA, M.E.; ARTHUR, F.H.; AKDOGAN, H. Temperature monitoring and aeration strategies for stored wheat in the central plains. In: ASAE ANNUAL INTERNATIONAL MEETING/CIGR WORLD CONGRESS, 15., 2002, Chicago. Proceedings... p.1-9 (ASAE, 02-6116).

DEVILLA, I.A.; COUTO, S.M.; QUEIROZ, D.M. Distribuição do fluxo de ar em silos com sistema de aeração: análise por elementos finitos. Revista Brasileira de Engenharia Agrícola e Ambiental, Campina Grande, v.9, n.2, p.256-262, 2005.

OLIVEIRA, F.A.; KHATCHATOURIAN, O.A.; BIHAIN, A. Estado térmico de produtos armazenados em silos com sistema de aeração: estudo teórico e experimental. Engenharia Agrícola, Jaboticabal, v.27, n.1, p.247-258, 2007.

RANALLI, R.P.; HOWELL JÚNIOR, A.; ARTHUR, F.H.; GARDISSER, D.R. Controlled ambient aeration during rice storage for temperature and insect control. Applied Engineering in Agriculture, Michigan, v.18, n. 4, p.485-490, 2002.

RIBEIRO, S.A.L.; CAVALCANTI, M.A.Q.; FERNANDES, M.J.S.; LIMA, D.M.M. Fungos filamentosos isolados de produtos derivados do milho comercializados em Recife, Pernambuco. Revista Brasileira de Botânica, São Paulo, v.26, n.2, p.223-229, 2003.

SAUER, D.B. Storage of grains and their products. 4th. St. Paul: American Association of Cereal Chemists, 1992. 
SILVA, J.S. Secagem e armazenagem de produtos agrícolas. Viçosa: Aprenda Fácil, 2000. 